\title{
Evolution of arthroscopic treatment from intracapsular to extracapsular for patients with refractory tennis elbow: A mixed-method study.
}

\section{Yu-ping Yang}

Peking University Third Hospital

Hong-ling Chu

Peking University Third Hospital

Shuo Yuan

Peking University Third Hospital

Hui Yan

Peking University Third Hospital

Jian Xiao

Peking University Third Hospital

Xu Cheng

Peking University Third Hospital

Hao Luo

Peking University Third Hospital

Yu-lei Liu

Peking University Third Hospital

Li-yuan Tao

Peking University Third Hospital

Yi-ming Zhao

Peking University Third Hospital

Guoqing Cui ( $\nabla$ cgq3019@vip.163.com )

Peking University Third Hospital https://orcid.org/0000-0003-1276-2195

\section{Research article}

Keywords: Qualitative, Quantitative, Tennis Elbow, Arthroscopy, Surgical Techniques

Posted Date: March 12th, 2020

DOI: https://doi.org/10.21203/rs.3.rs-16866/v1 
License: (c) (i) This work is licensed under a Creative Commons Attribution 4.0 International License. Read Full License 


\section{Abstract}

\section{Background}

Arthroscopic surgery is widely used in the treatment of refractory tennis elbow due to its advantages of minimally invasive, safe and direct vision. Intra-capsular arthroscopy(intracapsular method), which is performed via natural cavity, is the mainstream arthroscopic procedure. However, intracapsular method requires the damage of joint capsule and may cause intraoperative neurovascular injury and other complications. In view of the defects of intracapsular method, the surgical scheme of the extracapsular arthroscopy (referred to as "extracapsular method") has emerged. The aim of this study was to investigate the exploration history, key theories, methods, and techniques involved in the evolution from the intracapsular method to the extracapsular method for arthroscopic treatment of tennis elbow, and explore the effectiveness and safety of extracapsular method.

\section{Methods}

Qualitative data were collected via focus group interview. 7 surgeons who were selected through purposive sampling discussed on the theories, methods, and technical specifications of the transition from intracapsular method to extracapsular method. Qualitative data were analysed using NVivo11. Quantitative data of consecutive 43 patients were analysed to evaluate the effectiveness and safety of the extracapsular method. Descriptive analysis was conducted to analyse the demographic characteristics and clinical outcomes after surgery.

Results

The experts agreed that the extracapsular method maintains the integrity of joint capsule and avoids complications caused by joint capsule damage. Extracapsular method was considered easy for surgeons to master and convenient to operate. Technical specifications for extracapsular method were formed based on group discussion. The median time for pain relief and recovery of daily activities of 43 patients treated with these specifications were 3 months and 6 weeks, respectively. The satisfaction rates of Mayo Elbow Performance Scores were $87.2 \%, 95.6 \%$, and $100 \%$ respectively at 3,6 , and 12 months after operation.

\section{Conclusion}

On the basis of international peer innovation, the extracapsular method has been continuously developed in our clinical practice to avoid the possible complications of the intracapsular method. The resulting technical specifications have been shown to have good clinical efficacy and safety in a small sample cohort.

\section{Introduction}


Tennis elbow, also known as lateral epicondylitis, was first reported in 1873[1] and was named "tennis elbow" in 1883[2]. The incidence rate of tennis elbow is approximately $1.3 \%$. Tennis elbow not only occurs in tennis players (tennis players only account for $5 \%$ [3]), but also is closely related to smoking, poor social support and heavy physical labour [4]. The main manifestations of tennis elbow are localised tenderness of the lateral epicondyle and positive Mills' sign [5].

Approximately $90 \%$ of tennis elbow cases can be improved through conservative treatment within 6 months [6]. Surgical treatment should be considered when conservative treatment fails. Surgical treatment of tennis elbow can be classified into 3 types: open surgery, arthroscopic surgery, and percutaneous surgery $[6,7]$. Hohmann published the first paper on open surgery in 1926[8]. With the rapid development of elbow arthroscopy since the 1980s [9], Grifka et al. [10] begun to perform minimally invasive arthroscopic surgery on tennis elbow in 1995.

Arthroscopic intracapsular elbow surgery(intracapsular method) refers to an operation in which the natural cavity in the joint capsule is selected as the operate space. To expose the common extensor origin (CEO) outside of the joint capsule under arthroscopy, the capsule is opened from the inside of joint cavity, and the release or debridement is performed near the origin of extensor carpi radialis brevis (ECRB) [11, 12]. Intracapsular method soon became the mainstream surgical method for the treatment of refractory tennis elbow because of its minimally invasive nature, safety, and direct vision feature compared with open surgery. However, intracapsular method requires damage of the joint capsule, and intracapsular operation may cause intraoperative neurovascular injury and other complications. Due to these limitations of the intracapsular method, Rubenthaler et al.[13, 14] explored a new approach to arthroscopic treatment for tennis elbow, which was performed outside of the elbow joint capsule. Further studies conducted by us $[15,16]$ investigated the efficacy and specific surgical scheme of this extracapsular arthroscopy (referred to as "extracapsular method"), which was soon launched in our clinical practice.

Through qualitative interviews and quantitative research methods, this study is aimed at investigating the key theories, methods, and techniques involved in the transition from the intracapsular method to the extracapsular method, clarified the exploration history and technical specifications of extracapsular method, and explore the efficacy and safety of extracapsular method.

\section{Methods}

\subsection{Study Design}

In this study, the mixed methods exploratory sequential design was used. At first, using the method of qualitative research, a focus group interview was held among sports medicine surgeons. The aim of focus group interview was to understand the development of arthroscopic surgery for refractory tennis elbow, summarize the development history and summed up the technical specifications of the 
extracapsular method. The quantitative data were applied to evaluate the clinical application effect of the innovative extracapsular method. The research design is shown in Fig. 1.

\subsection{Qualitative \\ 2.2.1 Participants}

Sports medicine surgeons who were purposively sampled from an institute of sports medicine at a university hospital in China were sampled as participants. The institute, which is the first and largest sports medicine centre in China, offers sports trauma treatment, sports nutrition instruction, sports rehabilitation, and sports medical supervision. Annual outpatient visits to the institute exceed 100,000 and annual surgical procedures exceed 7400 . The institute has used arthroscopic techniques to treat refractory tennis elbow since 2002, with a specialised sports injury professional group for shoulder and elbow joints. In this study, 7 surgeons aged 37 to 53 years who had performed refractory tennis elbow surgery were included in a focus group interview. Detailed information of 7 surgeons is presented in Table 1.

Table 1

Characteristics of participants in the focus group discussion

\begin{tabular}{|lllll|}
\hline No. & Gender & Age & Years of surgery & Cumulative operation \\
\hline 1 & Male & 53 & 30 & 12,000 \\
\hline 2 & Male & 49 & 26 & 7,800 \\
\hline 3 & Female & 42 & 18 & 7,200 \\
\hline 4 & Male & 41 & 18 & 7,200 \\
\hline 5 & Male & 40 & 17 & 5,100 \\
\hline 6 & Male & 40 & 17 & 5,100 \\
\hline 7 & Male & 37 & 10 & 3,000 \\
\hline
\end{tabular}

\subsubsection{Data collection}

A semi-structured interview guide was developed based on a group discussion. In addition, we included specific questions on the topic and recorded conversations during the interview by every participants.

Focus group method was adopted to conduct the interview. One researcher presided over the interview, and 7 sports surgeons participated in the discussion. The dialogue prompts used in the focus group interview comprised the following: 1) "Please introduce yourself first, including age, expertise, time involved in arthroscopic tennis elbow surgery, and the number of surgical cases." 2) "Please discuss the development of arthroscopic tennis elbow surgery in our department." 3) "What is your opinion on arthroscopic surgery for refractory tennis elbow?" The interview was conducted in two rounds; the first 
round was preliminary investigation, and the second round was further inquiry on specific issues. The interview lasted 2.5 hours and was conducted in the participants' conference room, which was quiet and without interruption. The interview audio was recorded and transcribed verbatim.

\subsubsection{Data analysis}

The Chinese transcripts were analysed through thematic analysis using an inductive approach. Nvivo 11(QSR international Pty. Ltd., Australia) was used to assist in the analysis of the data. Two researchers ( $\mathrm{CH}$ and $\mathrm{YY}$ ) independently analysed and coded the transcripts by selecting units of analysis, understanding the transcripts, developing codes, categorising the data, and summarizing [17]. The analysts discussed and agreed on the coding and categorisation after reviewing one-fifth of the whole transcripts. The two researchers subsequently coded the remaining transcripts. Member checking was used to share the results with the participants in a discussion meeting. Comments from 7 responding participants identified no concerns with our interpretations.

\subsection{Quantitative}

\subsubsection{Participants}

43 consecutive Patients from March 2012 to January 2016 was collected retrospectively. Inclusion criteria included 1) Patient was aged between 18 and 45 years old; 2) Diagnosis was refractory tennis elbow; 3) Standard extracapsular method was used for surgery. Exclusion criteria included: 1) Patient had past history of joint infection, joint tuberculosis, or osteomyelitis, or the upper limb had undergone surgery within the past 6 months; 2) Diagnosis was combined with severe heart, brain, kidney, or another organ dysfunction; 3) Case was complicated with other serious elbow joint diseases or injuries; 4) Patient did not sign the informed consent form.

\subsubsection{Data collection}

Based on the record, the data of 43 patients were collected retrospectively. The data collected were basic demographic characteristics, efficacy indicators and prognosis indicators. The efficacy indicators were time for complete pain elimination and time to resume daily activities. Th e short-term prognosis indicators were Mayo Elbow Performance Score (MAYO), Disability of Arm, Shoulder and Hand Score (DASH), and Visual Analog Scale (VAS) at 3 months. The long-term prognosis indicators were MAYO, DASH, and VAS 12 months after surgery. Patients' postoperative complications, including vascular injury and nerve injury were recorded for the assessment of operative safety.

\subsubsection{Data analysis}

Statistical analysis was performed using SPSS for Windows, version 24.0(IBM, Armonk, NY, USA). Descriptive analysis was conducted to analyse the demographic characteristics and clinical outcomes after surgery.

\subsection{Ethical considerations}


The Peking University Third Hospital Ethics Review Board approved the study (2018-219-011), including the interviews and quantitative data use. Each participant was informed of the study procedures and was free to withdraw from the research. All participants provided written informed consent to participate in the interview, including the audio recording and transcription. Potentially identifying information was removed from each transcript, and each interviewee was assigned a unique identification number to protect anonymity.

\section{Results}

\subsection{Qualitative analysis}

The development of arthroscopic treatment for refractory tennis elbow at the institute and the current treatment standard of arthroscopic surgery for tennis elbow were clarified through interviews. The results are divided into three part: description of the development of refractory tennis elbow treatment, exploration of the advantages and specifications of the extracapsular method, and evaluation of the clinical application of the extracapsular method.

\subsubsection{Development of refractory tennis elbow treatment}

Through interviews and literature analysis, the development of refractory tennis elbow treatment was summarised in Table 2.

Table 2

The development of refractory tennis elbow treatment

\begin{tabular}{|c|c|c|c|}
\hline Project & The first stage & $\begin{array}{l}\text { The second } \\
\text { stage }\end{array}$ & The third stage \\
\hline $\begin{array}{l}\text { Development } \\
\text { content }\end{array}$ & Tennis elbow incision & $\begin{array}{l}\text { Arthroscopic } \\
\text { intra- } \\
\text { articular } \\
\text { treatment of } \\
\text { tennis elbow }\end{array}$ & $\begin{array}{l}\text { Arthroscopic Extracapsular Treatment of } \\
\text { Tennis Elbow }\end{array}$ \\
\hline $\begin{array}{l}\text { Reports of } \\
\text { International } \\
\text { Papers }\end{array}$ & $\begin{array}{l}\text { In 1926, Hohmann } \\
\text { invented an } \\
\text { international operation } \\
\text { to release the tendon of } \\
\text { extensor carpi radialis } \\
\text { brevis. }\end{array}$ & $\begin{array}{l}\text { In 1995, } \\
\text { Grifka } \\
\text { reported } \\
\text { arthroscopic } \\
\text { treatment of } \\
\text { tennis elbow }\end{array}$ & $\begin{array}{l}\text { In } 2005 \text {, Rubenthaler reported on their } \\
\text { previous exploration in this area in } 2005 \\
\text { The artificial subcutaneous space was } \\
\text { created to complete tendon treatment } \\
\text { outside the joint capsule }\end{array}$ \\
\hline $\begin{array}{l}\text { Technology } \\
\text { Application } \\
\text { of the } \\
\text { institute }\end{array}$ & $\begin{array}{l}\text { In } 1973 \text {, the institute } \\
\text { carried out the first } \\
\text { open surgery of tennis } \\
\text { elbow. }\end{array}$ & $\begin{array}{l}\text { Arthroscopic } \\
\text { treatment of } \\
\text { tennis elbow } \\
\text { began in } \\
2002 \text {. }\end{array}$ & $\begin{array}{l}\text { In 2005, extra-articular arthroscopy } \\
\text { (referred to herein as "extra-capsular } \\
\text { method") was started to treat refractory } \\
\text { tennis elbow. }\end{array}$ \\
\hline
\end{tabular}


In 1973, the institute began surgical treatment for tennis elbow, mainly through open-incision operations. In such operations, a large-scale release was made after incision, followed by $\mathrm{V}-\mathrm{Y}$ suture. Although the overall surgical effect was positive, the overall trauma remained considerable. Because of the maturation of arthroscopic surgery in other fields, the institute began using arthroscopy in the treatment of tennis elbow in 2002. Since then, the problems encountered have been resolved, and extracapsular method started in 2005.

\subsubsection{Exploration, advantages, and specifications of the extracapsular method}

Through focus group interviews, the improvement of the safety and convenience of the extracapsular method was discussed. Table 3 presents the improvement from intracapsular method to extracapsular method, and relevant quotations are provided in Appendix 1. 
Table 3

Disadvantages of Intracapsular Method and Corresponding Improvement of Extracapsular Method

\begin{tabular}{|c|c|c|c|}
\hline & Items & Intracapsular method & Extracapsular method \\
\hline \multirow[t]{3}{*}{ Safety } & $\begin{array}{l}\text { Nerve } \\
\text { injury }\end{array}$ & $\begin{array}{l}\text { The probability of vascular and nerve } \\
\text { bundle injury through the approach is } \\
\text { relatively high. }\end{array}$ & $\begin{array}{l}\text { There is almost no } \\
\text { possibility of damaging } \\
\text { vascular nerve bundles. }\end{array}$ \\
\hline & $\begin{array}{l}\text { Damage to } \\
\text { articular } \\
\text { capsule }\end{array}$ & $\begin{array}{l}\text { The tendon injury cannot be directly seen } \\
\text { ( } 28 \%-37.5 \% \text { have joint capsule tear, which } \\
\text { is relatively convenient for observation; } \\
\text { others need to open or even remove the } \\
\text { joint capsule first) }\end{array}$ & $\begin{array}{l}\text { Most of them do not } \\
\text { need to open or remove } \\
\text { the joint capsule. }\end{array}$ \\
\hline & $\begin{array}{l}\text { Tendon } \\
\text { suture }\end{array}$ & $\begin{array}{l}\text { Rupture of tendon and joint capsule is } \\
\text { difficult to suture and joint fluid } \\
\text { extravasation is easy to occur. }\end{array}$ & $\begin{array}{l}\text { Convenient suture to } \\
\text { reduce extravasation of } \\
\text { joint fluid }\end{array}$ \\
\hline \multirow[t]{4}{*}{ Convenience } & $\begin{array}{l}\text { Patient } \\
\text { posture }\end{array}$ & $\begin{array}{l}\text { The lateral position is generally required, } \\
\text { the positioning of the body position is } \\
\text { relatively complicated and takes a long } \\
\text { time. The patient's comfort is not good. }\end{array}$ & $\begin{array}{l}\text { Supine position is } \\
\text { sufficient, saving time } \\
\text { and labour, and the } \\
\text { comfort of patients is } \\
\text { better. }\end{array}$ \\
\hline & $\begin{array}{l}\text { Doctor's } \\
\text { perspective }\end{array}$ & $\begin{array}{l}\text { From the observation inside the joint } \\
\text { capsule, it is not easy to distinguish the } \\
\text { anatomical structure of several tendons } \\
\text { of the extensor total tendon, therefore, it } \\
\text { is more suitable for tendon release } \\
\text { operation, and tendon cleaning operation } \\
\text { is not easy. }\end{array}$ & $\begin{array}{l}\text { Observing from the } \\
\text { surface of extensor } \\
\text { tendon, it is easier to see } \\
\text { the anatomical structure } \\
\text { clearly, so it is more } \\
\text { suitable for cleaning the } \\
\text { tendon injury focus. }\end{array}$ \\
\hline & & $\begin{array}{l}\text { External epicondylar drilling } \\
\text { (microfracture) and decortication (due to } \\
\text { the limitation of the conventional anterior } \\
\text { medial observation approach, the tendon } \\
\text { insertion bone bed is observed from the } \\
\text { medial side of the joint, not directly) }\end{array}$ & $\begin{array}{l}\text { Observation from tendon } \\
\text { surface to joint direction } \\
\text { is direct vision. }\end{array}$ \\
\hline & $\begin{array}{l}\text { Learning } \\
\text { curve }\end{array}$ & $\begin{array}{l}\text { High technical threshold and long } \\
\text { learning curve }\end{array}$ & $\begin{array}{l}\text { The technical threshold } \\
\text { is relatively lower and the } \\
\text { learning curve is } \\
\text { relatively shorter. }\end{array}$ \\
\hline
\end{tabular}

1) Safety

Nerve injury

Extracapsular method allows surgeon to look at ECRB origin directly under the arthroscopy. In this case, surgeons can reach the damaged tissue more easily, and the risk of vascular and nerve injury is significantly reduced. The method is simple even to surgeons with little arthroscopy experience. Intracapsular evaluation can also be performed if necessary. 
Damage to the joint capsule

Because the extracapsular method gradually cleans from the tendon surface layer to deeper layers, damage to the joint capsule is minimal, and the joint capsule is opened only if it is itself damaged or the tendon deep layer connected to the joint capsule is obviously damaged. Therefore, the chance of liquid exudation due to joint capsule damage is minimal, and the risks of oedema and extracapsular effusion are also small.

Tendon and capsule suture

The ruptures of tendon and capsule are difficult to suture using intracapsular method, and joint fluid exudation can easily occur. However, it is convenient and safe to suture tendon ruptures outside the joint capsule under direct vision.

\section{2) Convenience}

Patient posture

The intracapsular method generally requires a stable lateral position, which is relatively complicated to achieve and takes a long time to set up, and the patient's comfort is limited. However, the extracapsular method can be applied in the supine position, which saves time and labour, and the patient's comfort is improved (Fig. 3).

Operator's perspective

In intracapsular method, CEO cannot be directly observed, and distinguishing the anatomical structure of CEOs is difficult. In addition, part of the joint capsule must be removed during the operation, and the viewing portal is at the medial side of elbow joint, which cannot offer a direct vision to the surface of lateral epicondyle; thus, the visual angle is not ideal. However, the viewing portal used in the extracapsular method, because it is from the surface of the extensor tendon, is almost direct to the bone surface of the lateral epicondyle (Fig. 4). Therefore, determining the positional relationship between the CEO tendon and the lateral epicondyle is simple, which is beneficial to the operation. In addition, drilling (microfracture) and decorticating operations performed on the lateral epicondyle are also facilitated because they are conducted under almost direct vision.

\section{Learning curve}

Because the intracapsular method requires damage of the joint capsule for exploration and operating from within the joint, a difficult arthroscopic technique for the elbow joint must be learnt. Therefore, the technical threshold is high, and the learning curve is steep. However, the direct extracapsular method requires only that the needle reach the lateral epicondyle of the humerus before operating, creating a gap in the subcutaneous layer for the operation without passing through the joint capsule. The technical threshold is thus relatively low, and the learning curve is relatively gradual. 
According to surgeons' practical observations and extensive discussion, the surgical specifications of the extracapsular method were summarised as follows:

a. Brachial plexus anaesthesia.

b. Supine position.

c. A needle is positioned on the lateral epicondyle, and two approaches are made at $3 \mathrm{~cm}$ proximal and distal of the lateral epicondyle. The length of approaches is $0.5 \mathrm{~cm}$ (Fig. 2).

d. A subcutaneous space is created, and the arthroscope is inserted through a proximal approach, and a planer tool is inserted through the distal approach.

e. Clean the surface of CEO. Look for weak or broken parts when cleaning. If found, use the scratch test principle to clean the damaged part.

f. In some patients with joint capsule rupture, intracapsular exploration can be performed directly.

g. If tearing (i.e. exposure of the bone bed) is observed at the tendon origin, decortication treatment should be performed.

$\mathrm{h}$. The remaining tendon on both sides of the slit is cleaned and percutaneously sutured with a needle and thread and PDS No.0, and the sutures are tied and fixed with 3-0 absorbable thread (Fig. 5).

\subsection{Evaluation of clinical application of extracapsular method}

Building upon the standard surgery method established from qualitative study, the quantitative data of 43 patients ( 14 men and 29 women) were reviewed. The minimum age was 35 years, and the maximum age was 55 years old, with an average of 44.4 years. Detailed data are presented in Table 4.

Table 4

Basic Demographics of Patients

\begin{tabular}{|lcl|}
\hline Items & N & Value \\
\hline Age $(\mathrm{m} \pm \mathrm{sd})$ & 43 & $44.4 \pm 5.2$ \\
\hline Gender & & \\
\hline Male & 14 & $32.6 \%$ \\
\hline Female & 29 & $67.4 \%$ \\
\hline Preoperative diagnosis & & \\
\hline Left tennis elbow & 12 & $27.9 \%$ \\
\hline Right tennis elbow & 31 & $72.1 \%$ \\
\hline
\end{tabular}

In this study, the median time to complete pain elimination was 3 months, and the median time to resume daily activities was 6 weeks. The short-term prognosis after surgery was 3 months. The mean MAYO, 
DASH, and VAS scores were 83.00, 24.05, and 2.80, respectively. The long-term prognosis after the operation was expressed as the mean MAYO, DASH, and VAS scores at 12 months after the operation; these scores were 96.41, 7.525, and 1.00, respectively, as indicated in Table 5. In addition, the 43 patients exhibited no complications, such as vascular injury or nerve injury.

Table 5

Prognostic Evaluation of Arthroscopic Extracapsular Therapy for Refractory Tennis Elbow

\begin{tabular}{|c|c|c|c|c|c|c|}
\hline Items & $\mathbf{N}$ & mean & $\begin{array}{l}\text { Standard } \\
\text { deviation }\end{array}$ & $\begin{array}{l}\text { Minimum } \\
\text { value }\end{array}$ & $\begin{array}{l}\text { Maximum } \\
\text { value }\end{array}$ & Median \\
\hline \multicolumn{7}{|l|}{ Curative effect } \\
\hline $\begin{array}{l}\text { Time for complete pain } \\
\text { elimination (months) }\end{array}$ & 39 & 4.70 & 5.27 & 0 & 24.00 & 3.00 \\
\hline $\begin{array}{l}\text { Time to resume daily activities } \\
\text { (weeks) }\end{array}$ & 42 & 7.68 & 6.74 & 1.0 & 32.0 & 6.00 \\
\hline $\begin{array}{l}\text { MAYO score } 3 \text { months after } \\
\text { surgery }\end{array}$ & 40 & 83.00 & 14.52 & 26.0 & 100.0 & 85.00 \\
\hline $\begin{array}{l}\text { DASH score } 3 \text { months after } \\
\text { operation }\end{array}$ & 40 & 24.05 & 19.53 & 1.67 & 88.33 & 21.25 \\
\hline $\begin{array}{l}\text { VAS score } 3 \text { months after } \\
\text { operation }\end{array}$ & 40 & 2.80 & 1.81 & 0.0 & 8.0 & 3.00 \\
\hline $\begin{array}{l}\text { MAYO score } 12 \text { months after } \\
\text { surgery }\end{array}$ & 39 & 96.41 & 6.17 & 85.0 & 100.0 & 100.00 \\
\hline $\begin{array}{l}\text { DASH score } 12 \text { months after } \\
\text { operation }\end{array}$ & 39 & 7.525 & 8.23 & 0.0 & 30.83 & 3.33 \\
\hline $\begin{array}{l}\text { VAS score } 12 \text { months after } \\
\text { operation }\end{array}$ & 39 & 1.00 & 1.30 & 0.0 & 4.0 & 0 \\
\hline \multicolumn{7}{|l|}{ Safety } \\
\hline Occurrence of complications & 39 & 0 & 0 & 0 & 0 & 0 \\
\hline
\end{tabular}

\section{Discussion}

\subsection{Safety issues}

The anatomical structure of the elbow joint is complex. The structures of joints, tendons, ligaments, nerves, and blood vessels are mutually adjacent and easily injured during operation. Common complications in intracapsular method includes temporary nerve injuries (forearm sensory abnormalities $[18,19]$, reflex sympathetic dystrophy syndrome [20]and radial nerve paralysis [21]), suture infection [13, 21, 22], and large hematoma [13]. Elbow joint instability, permanent nerve injury and deep infection are 
serious but rare complications [23]. In our study, no evident complications occurred, and the extracapsular method greatly improved the safety of the operation.

\subsection{Innovative proposal and application of extracapsular method}

Our institute has carried out the extracapsular method since 2004 and achieved satisfactory surgical results[15, 16, 24]. our study determined several advantages of the extracapsular method. (1) Anatomical structure of CEO is easy to identify, avoiding the speculation of the tendon lesion location in intracapsular method. (2) On the premise of protecting the radial collateral ligament, CEO is debrided to the maximum extent, and the risks of vascular and nerve injury are significantly reduced. (3) Debridement and arthroscopic suturing are convenient in extracapsular method. (4) The learning curve is gradual, and the method is simple even to surgeons inexperienced in arthroscopy. In 2008, Brooks-Hill et al. [14] published their experience in CEO debridement from outside the joint in the form of a technical report. Few clinical studies [13, 15, 24-27] on extracapsular method have been reported, but there are four Chinese studies[15, 24, 26, 27] from our institute, which demonstrates that the institute is an innovator of extracapsular method and has attracted the attention of other institutions. The quantitative data in the studies of our institute indicates that the operation appears to successfully avoids the complications that may be caused by the intracapsular method, and this finding is of great clinical significance.

\subsection{Clinical effect of extracapsular therapy}

In the quantitative part of our study, the average postoperative recovery time for daily activities was 6 weeks. The literature indicates that the median recovery time of the arthroscopic intracapsular method is 1.2 months, which is shorter than the recovery time reported in other studies. The median postoperative VAS in this study was 0, compared with 1.48[21] in the literature. In this study, the median MAYO and DASH were 100 and 3.33 respectively at 12 months after surgery, whereas the mean MAYO and DASH scores in the literature were 94.10 and 4.81[21], respectively. Rubenthaler et al.[13] reported that artificial subcutaneous space was created for tendon treatment outside the joint capsule, but they mainly discussed under-arthroscope release of the ECRB (referred to as the Hohmann operation) instead of the technical details such as whether the lateral epicondyle should be decorticated or drilled or whether the joint capsule needs to be sutured.

\subsection{Strengths}

In this study, the key theories, methods, and techniques involved during the evolution from the intracapsular method to the extracapsular method were summarised by integrating qualitative interviews and quantitative research methods. The exploration history of arthroscopic treatment for refractory tennis elbow using the extracapsular method and the technical specifications formed were clarified. The innovative technical exploration process is detailed and transparent, helping young surgeons to learn and understand it. This process lays a reference for further verification and promotion of the effectiveness and safety of the operation. 


\subsection{Limitations}

In our study, the quantitative evaluation data were insufficient, there was no parallel control, and the efficacy and safety of the extracapsular surgery group only were observed. However, this study integrated data from previous works, as mentioned in the discussion, and a mixed research method combining qualitative and quantitative methods was applied to overcome the shortcoming of using data from a single data source.

In addition, this study used only in one institute as the research location, presenting certain limitations in extrapolating the overall research results. However, the institute is the first sports medicine department in China its technology and its scientific research levels are among the highest at the national level, representing the most advanced sports medicine institution in the country. Therefore, innovation of new technologies in our centre has great influence. In addition, we did not find any other hospitals in China reporting the application of relevant technologies in the literature.

\section{Conclusion}

Based on qualitative and quantitative methods, We recognized that the extracapsular method, which has been developed in clinical practice by international peers, avoids the complications of the intracapsular method. The technical specifications demonstrated good clinical efficacy and safety in a small cohort sample.

\section{Abbreviations}

CEO: common extensor origin; ECRB: extensor carpi radialis brevis; MAYO: Mayo Elbow Performance Score; DASH: Disability of Arm, Shoulder and Hand Score; VAS: Visual Analog Scale

\section{Declarations}

\section{Acknowledgement}

We sincerely thank all the participants who made this research possible.

\section{Authors' contributions}

YY was responsible for surgery operation, study design and part of the article writing. $\mathrm{HC}$ was responsible for implementation and discussion of the qualitative part, as well as writing of statistical analysis part. SY was responsible for clinical data collection, patient follow-up and article writing. YZ and GC were responsible for study conception and instruction. HY, JX, XC, HL, YL contributed to study design and implementation. LT contribute to statistical analysis of qualitative data and quantitative data. All authors discussed the results and commented on the drafts of the manuscript. All authors have read and approved the final version of the manuscript. 


\section{Funding}

This study was funded by National Key research and development program of China(2019YFF0302305).

The funders had no role in the study design, data collection and analysis, decision to publish, or preparation of the manuscript.

\section{Availability of data and materials}

The transcripts, qualitative data and quantitative data used and/or analysed during the current study are available from the corresponding author on reasonable request.

\section{Ethic approval and consent to participate}

The Peking University Third Hospital Ethics Review Board approved the study(No. 2018-219-011). Obtained written consent.

\section{Consent for publication}

Written consent was obtained from every participant for data publication.

\section{Competing interests}

All authors declare no competing interests.

\section{References}

1. Runge F: Zur genese und behandlung des schreibekrampfes. Berl Klin Wochenschr 1873, 10:245-248.

2. Morris H: Lawn tennis elbow. Br Med J 1883, 2:557.

3. Waseem M, Nuhmani S, Ram C, Sachin Y: Lateral epicondylitis: a review of the literature. Journal of back and musculoskeletal rehabilitation 2012, 25(2):131-142.

4. Winston J, Wolf JM: Tennis elbow: definition, causes, epidemiology. In: Tennis Elbow: Clinical Management. edn. Edited by Wolf JM. Boston, MA: Springer US; 2015: 1-6.

5. Dogramaci Y, Kalaci A, Savaş N, Duman IG, Yanat AN: Treatment of lateral epicondilitis using three different local injection modalities: a randomized prospective clinical trial. Archives of orthopaedic and trauma surgery 2009, 129(10):1409-1414.

6. Solheim E, Hegna J, Oyen J: Arthroscopic versus open tennis elbow release: 3- to 6-year results of a case-control series of $\mathbf{3 0 5}$ elbows. Arthroscopy 2013, 29(5):854-859.

7. Dunkow P, Jatti M, Muddu B: A comparison of open and percutaneous techniques in the surgical treatment of tennis elbow. The Journal of bone and joint surgery British volume 2004, 86(5):701-704.

8. Hohmann G: Über den tennisellenbogen. Verh Dtsch Orthop Ges 1927, 21(1):349-354.

9. Khanchandani P: Elbow arthroscopy: review of the literature and case reports. Case reports in orthopedics 2012, 2012. 
10. Grifka J, Boenke S, Krämer J: Endoscopic therapy in epicondylitis radialis humeri. Arthroscopy 1995, 11(6):743-748.

11. Soeur L, Desmoineaux P, Devillier A, Pujol N, Beaufils P: Outcomes of arthroscopic lateral epicondylitis release: Should we treat earlier? Orthop Traumato/ Surg Res 2016, 102(6):775-780.

12. Solheim E, Hegna J, Oyen J, Inderhaug E: Arthroscopic Treatment of Lateral Epicondylitis: Tenotomy Versus Debridement. Arthroscopy 2016, 32(4):578-585.

13. Rubenthaler F, Wiese M, Senge A, Keller L, Wittenberg RH: Long-term follow-up of open and endoscopic Hohmann procedures for lateral epicondylitis. Arthroscopy 2005, 21(6):684-690.

14. Brooks-Hill AL, Regan WD: Extra-articular arthroscopic lateral elbow release. Arthroscopy 2008, 24(4):483-485.

15. Yan H, Cui GQ, Liu YL, Xiao J, Yang YP, Ao YF: [A randomized comparison of open and arthroscopic Nirschl debridement for refractory lateral epicondylitis]. Zhonghua Wai Ke Za Zhi 2009, 47(12):888891.

16. Yang YP, Yuan S, Li N, Ao YF: Analysis of factors influencing the efficacy of extracapsular arthroscopic surgery for refractory tennis elbow. Zhonghua wai ke za zhi [Chinese journal of surgery] 2019, 57(11):818-823.

17. Thorne S: Data analysis in qualitative research. Evidence-based nursing 2000, 3(3):68-70.

18. Lattermann C, Romeo AA, Anbari A, Meininger AK, McCarty LP, Cole BJ et al: Arthroscopic debridement of the extensor carpi radialis brevis for recalcitrant lateral epicondylitis. $J$ Shoulder Elbow Surg 2010, 19(5):651-656.

19. Terra BB, Rodrigues LM, Nahssen Filho A, de Almeida GDB, Cavatte JM, De Nadai A: Arthroscopic treatment for chronic lateral epicondylitis. Revista Brasileira de Ortopedia (English Edition) 2015, 50(4):395-402.

20. Peerbooms JC, Sluimer J, Bruijn DJ, Gosens T: Positive effect of an autologous platelet concentrate in lateral epicondylitis in a double-blind randomized controlled trial: platelet-rich plasma versus corticosteroid injection with a 1-year follow-up. The American journal of sports medicine 2010, 38(2):255-262.

21. Babaqi AA, Kotb MM, Said HG, AbdelHamid MM, ElKady HA, ElAssal MA: Short-term evaluation of arthroscopic management of tennis elbow; including resection of radio-capitellar capsular complex. J Orthop 2014, 11(2):82-86.

22. do Nascimento AT, Claudio GK: Arthroscopic surgical treatment of recalcitrant lateral epicondylitis-A series of 47 cases. Revista Brasileira de Ortopedia (English Edition) 2017, 52(1):46-51.

23. Pomerantz ML: Complications of lateral epicondylar release. Orthopedic Clinics 2016, 47(2):445-469.

24. Yang YP, Yuan S, Tao LY, An N, Ren J, Yan H et al: Surgical technique and curative effect analysis of extra-articular arthroscopic treatment of refractory tennis elbow: reports of 21 cases of mid-and-long term follow-up results. Chin J Minimally Invasive Surg 2019, 19(3):202-205. 
25. Cohen MS, Romeo AA, Hennigan SP, Gordon M: Lateral epicondylitis: anatomic relationships of the extensor tendon origins and implications for arthroscopic treatment. J Shoulder Elbow Surg 2008, 17(6):954-960.

26. Liu YL, Cui GQ, Ao YF, Xiao J, Yan H, Yu CL: The outcome of arthroscopic nirschl debridement for refractory lateral epicondylitis and the clinical value of the arthroscopic classification system. Chin $J$ Joint Surg (Electronic Edition) 2007, 1(5):319-324.

27. Liu YL, Cui GQ, Ao YF, Xiao J, Yan H, Yu CL: Influencing factors of arthroscopic Nirschl debridement for refractory tennis elbow. Chin J Sports Med 2007, 26(4):444-447.

\section{Figures}

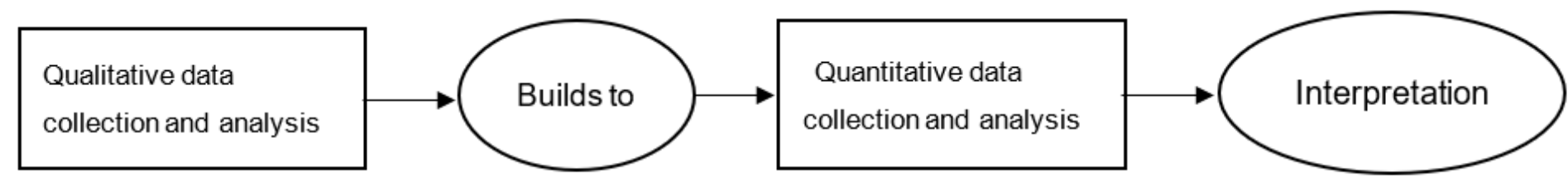

-Interview: Sports Medicine Doctor

-Objective: To clarify the innovative process of the extracapsular method and refine the postoperative standard of the extracapsular
-Data collection: HIS system

-Objective: Clinical evaluation of the effect and safety of this innovative extracapsular method

\section{Figure 1}

Research on Mixed-Methods through Exploratory Sequence Design 


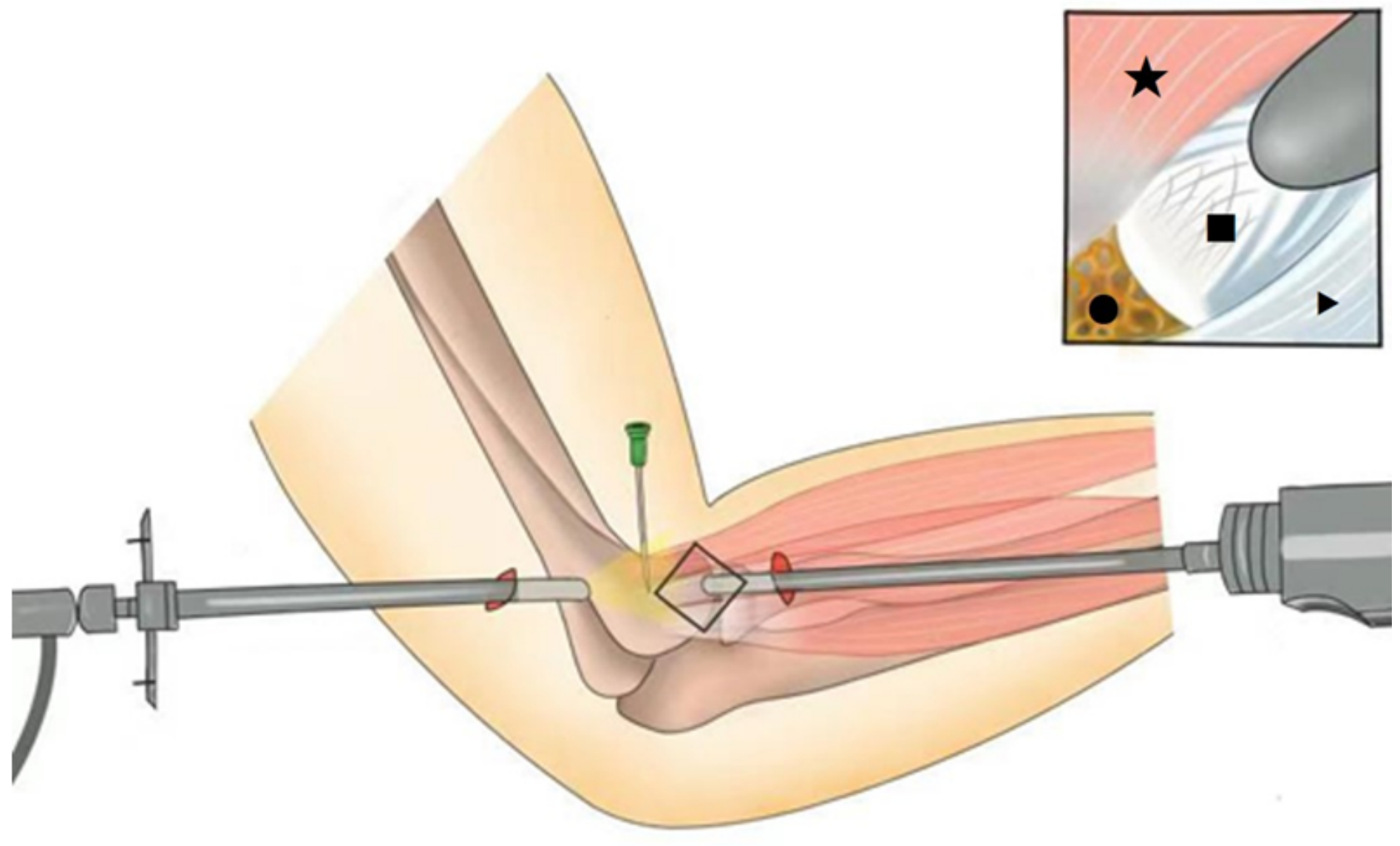

Figure 2

Schematic of an arthroscopic operation using the extracapsular method. Note: $\otimes$ Extensor carpi radialis longus; tendon extensor digitorum total; $\boldsymbol{\square}$ stump of ECRB tendon; exposed bone bed of lateral epicondyle of the humerus (after decortication) 


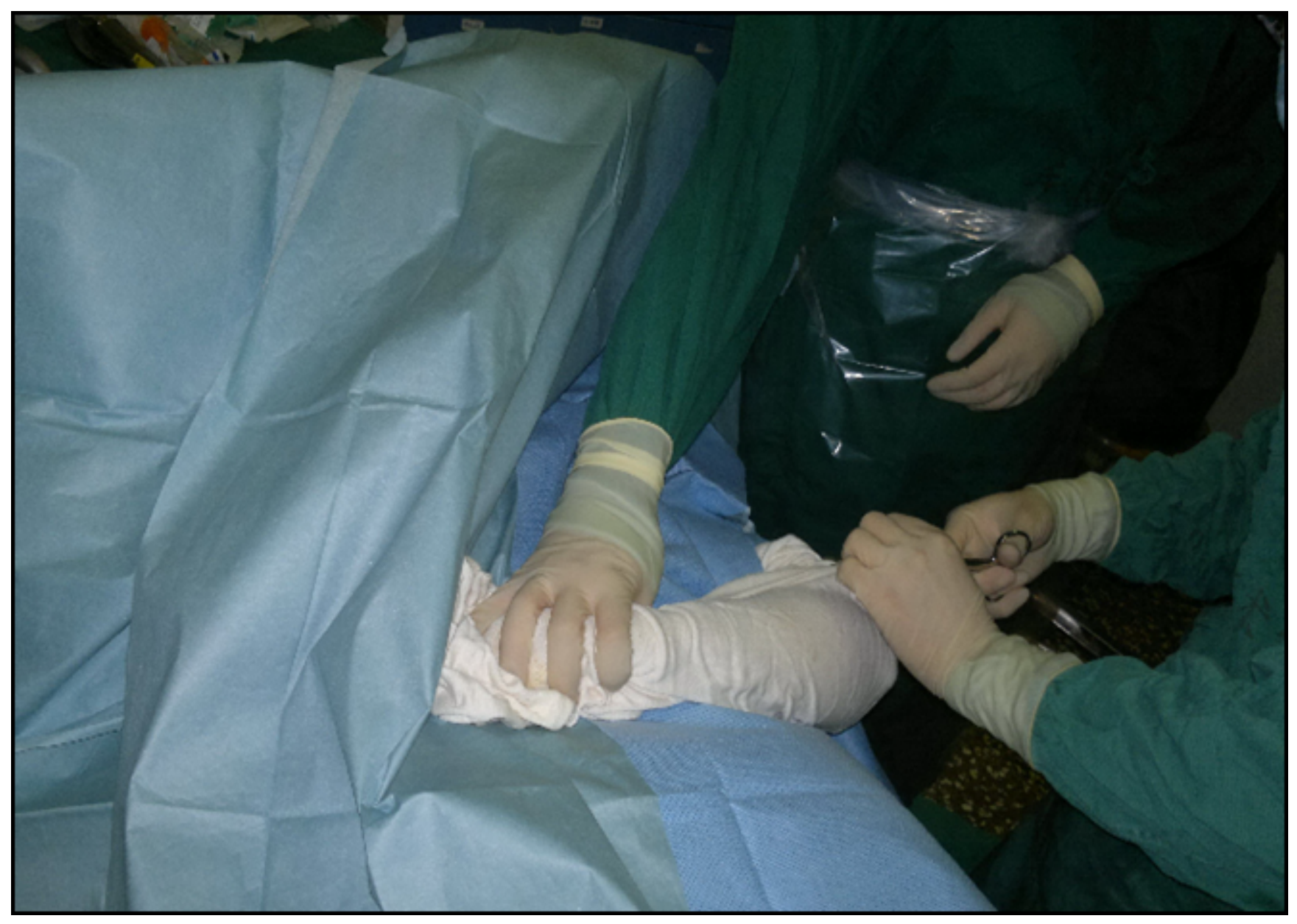

Figure 3

Postural diagram of the extracapsular method. Routine supine position is adequate. Brachial plexus anaesthesia. 


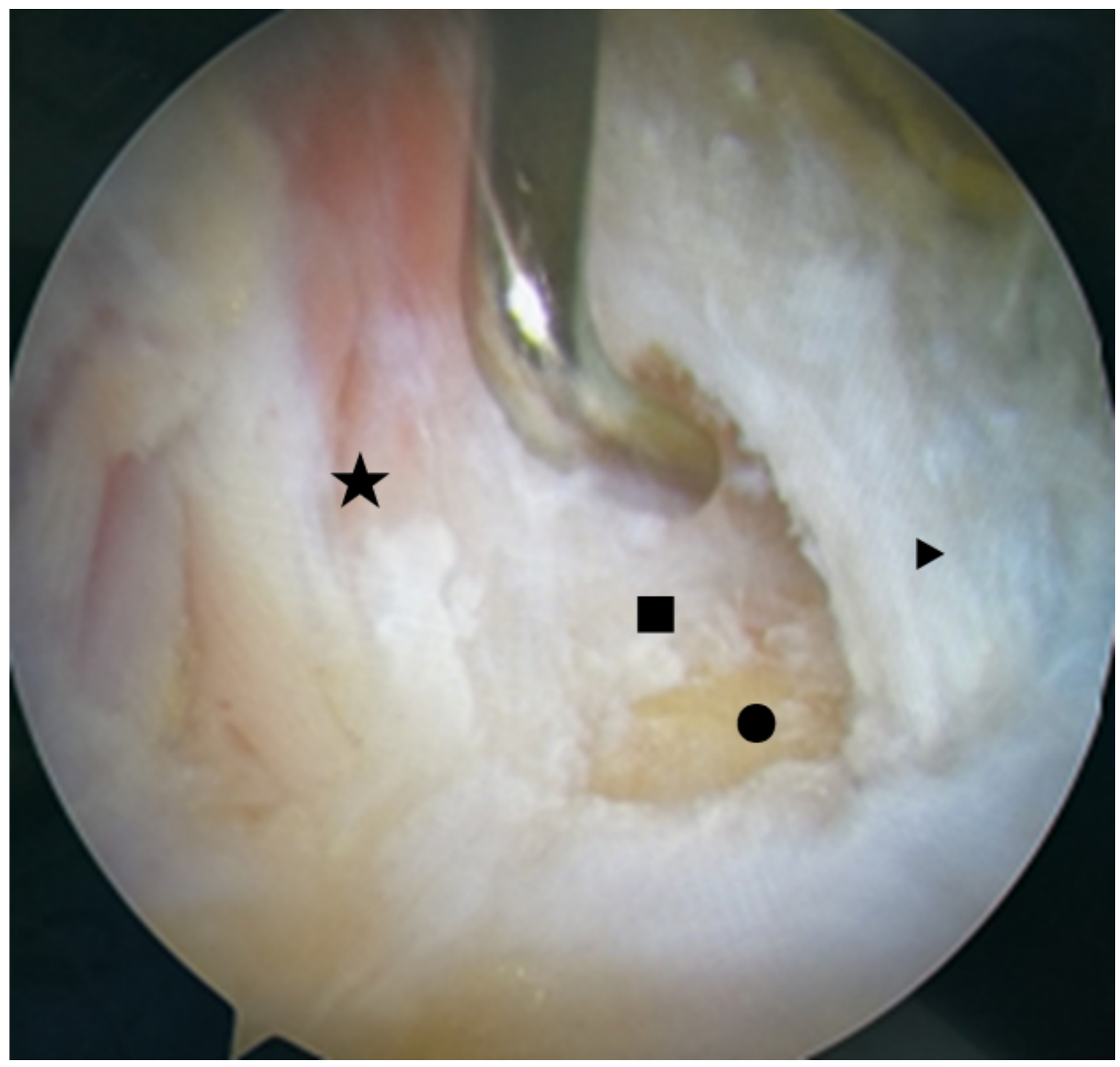

\section{Figure 4}

Extracapsular arthroscopic debridement. Note: $₫$ Extensor carpi radialis longus; $\square$ Stump of ECRB tendon (remaining superficial layer of tendon after cleaning); exposed bone bed of lateral epicondyle (after decortication); relatively intact upper surface layer of the ECRB tendon (intratendinous tearing occurs between the upper and lower surface layers).

2

\section{Figure 5}

Tendon rupture after arthroscopic suturing and repair using the extracapsular method. Note: The rupture on the ECRB tendon was well closed after suturing. 